\title{
Recent Evidence of Large-Scale Receding Snow Water Equivalents in the European Alps ${ }^{\mathscr{O}}$
}

\author{
CHRISTOPH MARTY \\ WSL Institute for Snow and Avalanche Research SLF, Davos, Switzerland \\ ANNA-MARIA TILG \\ WSL Institute for Snow and Avalanche Research SLF, Davos, Switzerland, and \\ University of Innsbruck, Innsbruck, Austria \\ TOBIAS JONAS \\ WSL Institute for Snow and Avalanche Research SLF, Davos, Switzerland
}

(Manuscript received 4 August 2016, in final form 5 January 2017)

\begin{abstract}
Snow plays a critical role in the water cycle of many mountain regions and heavily populated areas downstream. In this study, changes of snow water equivalent (SWE) time series from long-term stations in five Alpine countries are analyzed. The sites are located between 500 and $3000 \mathrm{~m}$ above mean sea level, and the analysis is mainly based on measurement series from 1 February (winter) and 1 April (spring). The investigation was performed over different time periods, including the last six decades. The large majority of the SWE time series demonstrate a reduction in snow mass, which is more pronounced for spring than for winter. The observed SWE decrease is independent of latitude or longitude, despite the different climate regions in the Alpine domain. In contrast to measurement series from other mountain ranges, even the highest sites revealed a decline in spring SWE. A comparison with a 100-yr mass balance series from a glacier in the central Alps demonstrates that the peak SWEs have been on a record-low level since around the beginning of the twenty-first century at high Alpine sites. In the long term, clearly increasing temperatures and a coincident weak reduction in precipitation are the main drivers for the pronounced snow mass loss in the past.
\end{abstract}

\section{Introduction}

Snow on the ground is a decisive feature of winter in many mountain regions. The impacts of the snow cover range from avalanche hazard to essential ecological services. In the Alps, the seasonal snow cover is an important water resource and an indispensable requirement for winter tourism. There are three basic properties used to describe a snow cover-snow depth, snow density, and snow water equivalent (SWE)-and they are all interconnected with each other by the fact that snowpack density together with snow depth determines the SWE.

Supplemental information related to this paper is available at the Journals Online website: http://dx.doi.org/10.1175/ JHM-D-16-0188.s1.

Corresponding author e-mail: Christoph Marty, marty@slf.ch
Snow depth is by far the simplest and therefore most frequently measured and analyzed parameter. On the other hand, measurements of SWE or snow density are either costly or time consuming and therefore typically sparse. However, these parameters influence the thermal, mechanical, and optical properties of snow. They are therefore important parameters for snow-related research and its applications, including snow hydrology (Magnusson et al. 2015), snow load estimation (Sadovský et al. 2012), snow model development (Lehning et al. 1999), avalanche hazard assessment (Mock and Birkeland 2000), numerical weather prediction (Franz et al. 2008), climate modeling (Steger et al. 2013), hydrological forecasting (Jörg-Hess et al. 2015), water resource management (Stewart 2009), and ecology (Jonas et al. 2008).

Because of the limited number of long-term datasets, there are only a few SWE trend studies, and most of them are focused on North America. For example, a 
general decrease in spring SWE was found for western North America (Mote et al. 2005) and the northeastern United States (Hodgkins and Dudley 2006). However, at some high-elevation areas in California, increasing SWE values were observed simultaneously (Howat and Tulaczyk 2005; Mote et al. 2005). Similarly, long-term SWE time series from Norway showed significant negative as well as significant positive trends, depending on the elevation and time periods considered (Skaugen et al. 2012). In Japan, SWE has only been measured since the beginning of the 1990s. Yamaguchi et al. (2011) did not observe a clear trend of the maximum of SWE but high interannual variations. In the Alps our knowledge of SWE changes is still strongly limited by the fact that measurements are sparse and data are hard to obtain from the different European countries. Rohrer et al. (1994) found no trend for SWE in the Swiss Alps for the period 1975-92. Bocchiola and Diolaiuti (2010) showed that the spring SWE values in the region of the Adamello Glacier in Italy decreased between 1965 and 2007. No analysis of SWE measurements has been performed so far for the entire Alpine region. Such an investigation is necessary to understand the climate-induced changes of the Alpine snow water resources and to improve large-scale gridded SWE datasets, which are rare, shorter, and show the largest uncertainties in complex mountain terrain like the Alps (Mudryk et al. 2015). This study found mostly negative SWE trends for the Northern Hemisphere and weak nonsignificant decreases in the Alps for the investigated period between 1982 and 2010.

The objective of this study is therefore to perform the first Alpine-wide analysis of temporal SWE changes since the beginning of a large number of operational measurements in 1945. We will analyze if these changes depend on elevation, climatic region, or season. Furthermore, we will investigate how the changes are linked to the corresponding changes in temperature and precipitation.

\section{Data and methods}

Dozens of national and regional weather, avalanche, and hydrological services were asked for long-term SWE data. In the case of France and Italy, only hydropower companies were able to fulfill our requirement for at least 30 years of long-term SWE series. After many inquiries, data from more than 80 stations from Austria, France, Germany, Italy, and Switzerland could be used for further assessment. Some stations could not be considered, because metadata showed relocations with elevation differences of more than $100 \mathrm{~m}$ or because outliers (in relation to neighbors) were detected. Further stations had to be omitted because data from more than five continuous years were missing. Finally, the analysis was limited to 54 stations with SWE measurements since at least 1968, which was the best compromise between station availability and series length. These remaining long-term stations cover elevations between 500 and $3000 \mathrm{~m}$ MSL, whereas the majority of the stations are located between 1300 and $2000 \mathrm{~m}$ MSL. There is a slight spatial bias because stations below $900 \mathrm{~m}$ are only available from Germany and Austria. The longest available series go back to the 1930s. However, the majority of the measurements started in the 1960s. Our analysis mainly focuses on the 45 years between 1968 and 2012, but trends for longer and shorter periods are also discussed.

The measurements were accomplished in flat measurement fields by either manually weighing a snow sample in the case of Austria, Germany, Italy, and Switzerland or by automatically measuring the attenuation of cosmic rays through the snowpack, as is done in France. Depending on the provider, the data were available weekly, biweekly, monthly, or only annually. We focus on the two index dates 1 February and 1 April because of data availability and in order to compare season-dependent changes. The corresponding SWE data are hereafter called "February SWE" (winter SWE) and "April SWE" (spring SWE). February SWE usually represents a cold winter snowpack and April SWE roughly corresponds to the time of maximum mountain snowpack. We are aware of the fact that peak SWE occurs earlier (later) at the lowest (highest) stations. However, this "bias" is constant for each site and therefore does not hamper the analysis. Moreover, a separate analysis has revealed (not shown) that peak SWE of Alpine catchments indeed occurs around 1 April.

The data series from most of the providers consisted of SWE values and the corresponding snow depth values, while one data provider supplied SWE values only. If possible, the snow density was calculated from snow depth and SWE in order to check the plausibility of the data. The highest accepted density was set to $600 \mathrm{~kg} \mathrm{~m}^{-3}$. This threshold was very rarely exceeded, since the data providers quality checked their data series before releasing them for distribution. Because of increasing measurement uncertainty with decreasing snow depth, SWE values were generally only provided when the snow depth was at least $10 \mathrm{~cm}$. For consistency, this threshold has been applied to all data series. The proportion of missing values is small. An analysis based on the $45-\mathrm{yr}$ period showed that on average only $9 \%$ (maximum 15\%) of the values from a station were missing. To have a complete series for the statistical analysis, these missing values were parameterized. A method based on the parameterization developed by Jonas et al. (2009) has been used. This method correlates 
snow density and snow depth dependent on season, elevation, and climatological region. We were able to improve this approach by deriving a station-specific calibration from the large amount of available data and by using daily instead of monthly regression values in order to prevent steplike changes between different months. In contrast to the other tested methods [the original parameterization developed by Jonas et al. (2009) and an approach shown by Rohrer and Braun (1994), which also requires daily new snow height], this approach produced the lowest absolute mean bias errors and is generally applicable because only snow depth is used as input. The chosen method is able to parameterize SWE with a relative root-mean-square error (RMSE) that decreases from about $30 \%$ at elevations below $1000 \mathrm{~m}$ MSL to about $15 \%$ at elevations above $1200 \mathrm{~m}$ MSL. Schöber et al. (2015) demonstrated that the performance of more sophisticated approaches is not better than this relatively simple approach. It should also be noted that the natural onsite variability of SWE and hence the uncertainty of single point measurements is typically between $10 \%$ and $20 \%$ (Jonas et al. 2009).

Since there is generally no meteorological data available from the used SWE stations, we used gridded time series, which were compiled by the Met Office Hadley Centre from long-term station data. The temperature and precipitation data are taken from the monthly gridded CRU Time Series, version 3.23, with a horizontal resolution of $0.5^{\circ}$ (Harris and Jones 2015). Data were extracted and averaged horizontally over the Alpine part of central Europe $\left(45.5^{\circ}-47.5^{\circ} \mathrm{N}, 6^{\circ}-12^{\circ} \mathrm{E}\right)$.

To analyze possible long-term changes, we applied the nonparametric Mann-Kendall (MK) test, which is based on rank-transformed time series, where only the relative magnitude of the measurement is considered. A positive standardized MK value indicates an increasing trend, while a negative value demonstrates a decreasing one. Confidence levels of $95 \%$ are used as a threshold to classify a significant trend $(p<0.05)$ and confidence levels of $80 \%$ are used to classify a weakly significant trend $(0.05<p<0.2)$. The strength of a trend was determined with a robust simple linear regression with the help of the Theil-Sen slope estimator (e.g., Gocic and Trajkovic 2013). Absolute and relative changes since the beginning of the investigated time period were calculated (for a detailed explanation, see the supplemental material) and plotted against elevation and geographical location. Note that the conversion from absolute to relative changes can in rare cases lead to an apparent loss exceeding $100 \%$ at a few stations (i.e., more than a $100 \%$ decrease in SWE), in cases where the line of best fit passes through zero sometime before the end of the investigated period, indicating that this site observed most likely no snow at all in the last few years.

\section{Results}

\section{a. Elevation-dependent changes}

The available SWE data cover a large elevation range from almost $500 \mathrm{~m}$ MSL in the Alpine foothills to more than $3000 \mathrm{~m}$ MSL in high-Alpine measurement fields. An analysis of the SWE data of the last 45 years shows a trend toward decreasing SWE at all elevations for both index dates. There is no station with a significant positive slope for any date.

For February SWE, the large majority of all stations show negative slopes, but only $11 \%$ (six stations) reveal a significant or weakly significant decrease (Fig. 1). The SWE reduction is only slightly dependent on elevation, although the largest significant relative decrease $(\sim 90 \%)$ is observed at the lowest station.

For April SWE, all stations show negative slopes and $54 \%$ (29 stations) reveal a significant or weakly significant decrease (Fig. 2). In contrast to February, the April SWE reduction clearly depends on elevation. The absolute SWE loss increases with elevation whereas the relative SWE loss decreases from about $90 \%$ at the lowest elevation to about $50 \%$ at the highest elevation. The significant changes are more or less uniformly distributed at all elevations.

The observed larger SWE spring reduction at higher elevations implies that there are no high stations with spring SWE increases as observed in Norway (Skaugen et al. 2012) or in the Sierra Nevada (Howat and Tulaczyk 2005). Both of these studies attributed these SWE increases at high elevations to changing precipitation amounts, which will be analyzed in the next paragraph.

\section{b. Region-dependent changes}

The investigated dataset not only covers a large elevation range but also a wide range of different climate regions stretching from southern France in the west to central Austria in the east and from the northern Alpine foothills in southern Germany to the southern Alpine foothills of northern Italy. A spatial analysis demonstrates that strength or significance of the SWE reduction is independent of the geographical position for both index dates (Figs. 3, 4).

\section{c. Time-period-dependent changes}

So far we focused on the 45-yr trends between 1968 and 2012, because this time period represents the best balance between data availability and spatial coverage. As the direction and strength of a trend can strongly 


\section{February 1}
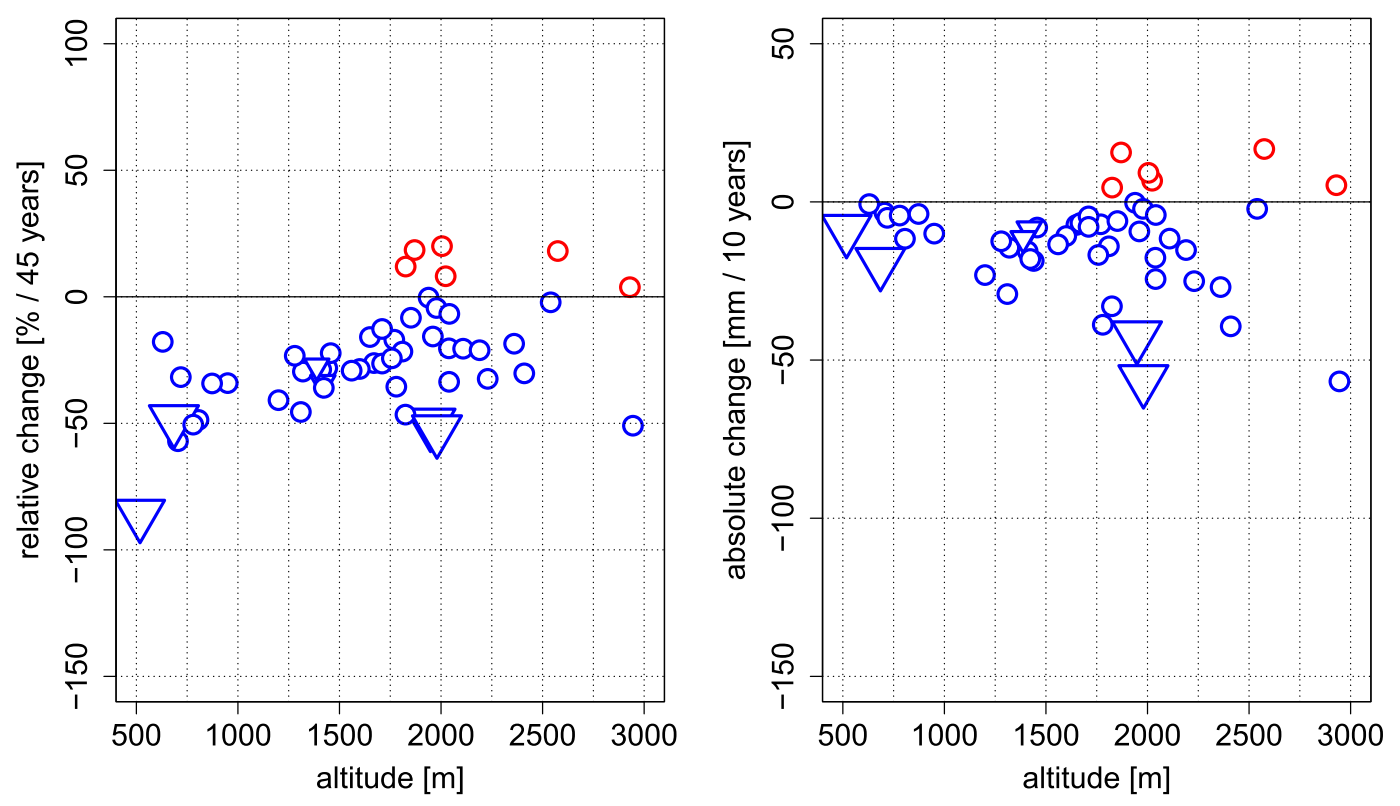

$\circ$ no trend $\quad \triangle$ positive trend $\nabla$ negative trend

FIG. 1. February (left) relative and (right) absolute SWE trends (1968-2012) of the individual stations. Blue specifies a negative trend, red specifies a positive trend. Large triangles indicate significant trends $(p<0.05)$ and small triangles indicate weakly significant trends $(p<0.2)$. Circles represent stations with no significant trend $(p \geq 0.2)$.

depend on the start and end dates, longer and shorter time periods were also investigated to check for the consistency of the trend and to understand the underlying causes. The start of the investigated time period has been limited to 1945, because there were too few stations available before then. An Alpine-wide SWE time series was constructed by calculating the relative SWE deviation from its long-term mean (1961-90) for each station and taking the median of these deviations for each year (for a detailed explanation, see the supplemental material).

The February SWE time series shows a sharp drop in the late 1980s, which causes all but the shortest time period (30 years) to be weakly significantly negative, while the trend slopes of the 40-, 50-, and 60-yr periods are very similar (Fig. 5). This long-term SWE reduction is clearly visible, as the lowest SWE values were all observed in the last three decades. The last 30-yr period (1983-2012), however, demonstrates no discernible trend.

The April SWE time series reveals decreasing trends for all time periods, whereas only the 40- and 50-yr time periods are significantly negative (Fig. 6). The mean of the last 30-yr period is definitely the lowest of the whole time series, but single low values are also evident in the 1950s and 1960s.
The SWE trends in Figs. 5 and 6 reveal mostly decreasing SWE amounts for all time periods and for both index dates. Nevertheless, for February a few higherelevation stations also show increases, although insignificantly (Fig. 1). The clear elevation dependence of the SWE decrease in April, in contrast to February, is in agreement with the findings of Bocchiola and Diolaiuti (2010) for the Adamello Glacier in Italy.

\section{d. Connection to temperature and precipitation}

The amount of SWE is mainly the result of an interplay between the development of precipitation and temperature during a season. This implies that SWE is sensitive to these two parameters and their history throughout the snow season. To investigate this dependency, the SWE trends are qualitatively compared with concurrent variability and trends in temperature and precipitation. The analyzed temperature and precipitation trends are based on CRU data. A comparison with a homogenized longterm dataset from Switzerland (Begert et al. 2005) and the Historical Instrumental Climatological Surface Time Series of the Greater Alpine Region (HISTALP) database (Auer et al. 2007) revealed almost identical results (Fig. S1 in the supplemental material), which is in agreement with the high correlation between Alpine station temperatures 
April 1
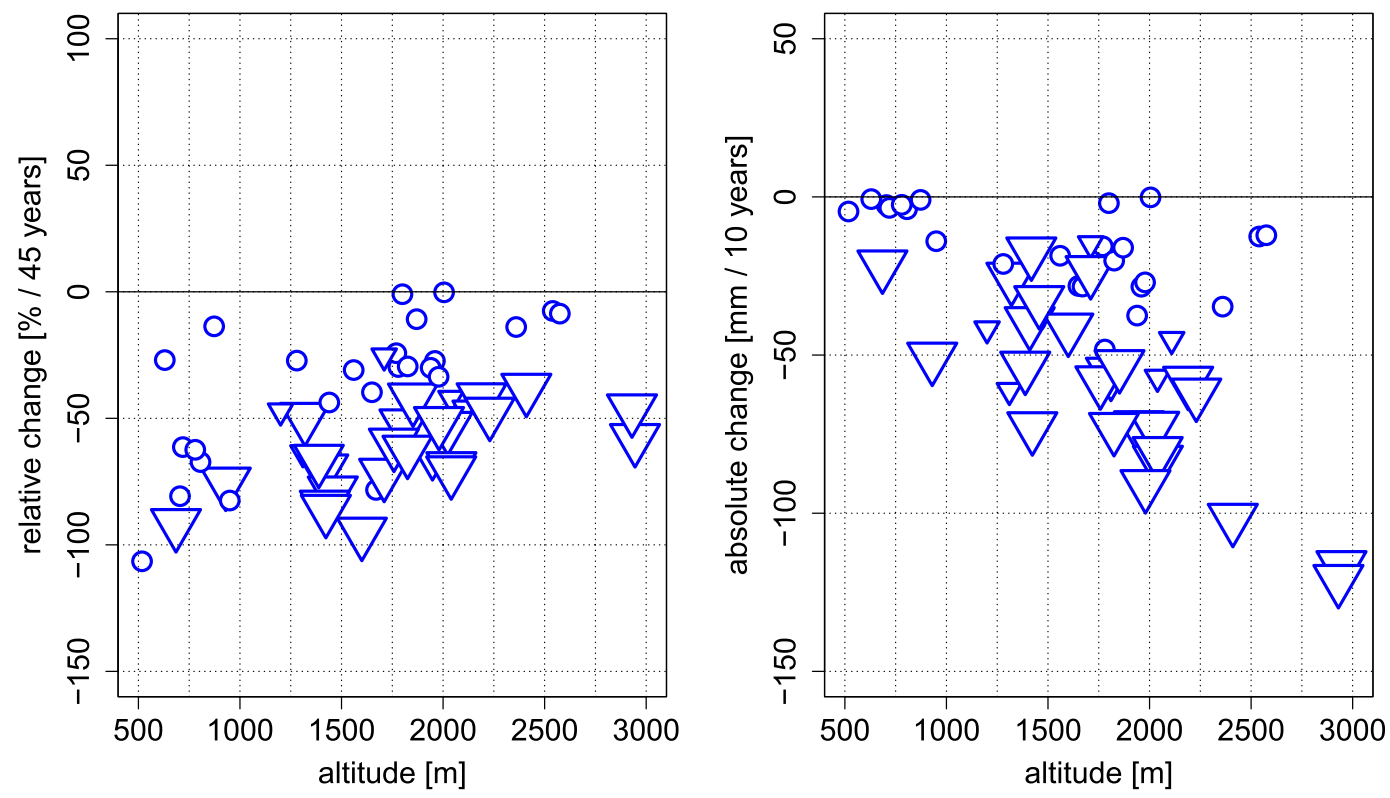

$\circ$ no trend $\Delta$ positive trend $\nabla$ negative trend

FIG. 2. As in Fig. 1, but for April.

and CRU temperature over a similar domain described in Hantel and Maurer (2011).

According to a correlation analysis, February SWE is best controlled by December-January temperatures and precipitation; other combinations of months resulted in weaker correlations. The corresponding comparison reveals that the slightly increasing SWE in the last 30 years can be associated with slightly decreasing temperatures (Fig. 7 and Fig. S2 in the supplemental material). This pattern of decreasing temperatures in the winter months in the recent decades was already described by Cohen et al. (2012) for large areas in the Northern Hemisphere and by Scherrer et al. (2013) for the Swiss Alps. The possible explanations for this temperature development comprise atmospheric internal variability ( $\mathrm{Li}$ et al. 2015), increasing Eurasian snow cover, or shrinking sea ice (Cohen et al. 2012). For all the other (longer) time periods, February SWE decreases can clearly be linked to temperature increases and concurrent slight decreases in precipitation. Moreover, the sharp drop of SWE in the late 1980s can clearly be attributed to a concurrent steplike increase in temperature, which has already been documented for the Alps by Marty (2008), but also on the global scale by Reid et al. (2016).

A similar explanation can also be found for the April SWE, which is best controlled by December-March temperatures and precipitation. The analysis reveals that the decreasing SWE for all time periods can be linked to an increase in temperature, the effect of which is enhanced by simultaneous decreases in precipitation (Fig. 7 and Fig. S3 in the supplemental material). A similar precipitation decrease could be found when analyzing 12 Alpine stations from Switzerland with homogenized precipitation data (not shown) and was also found by Scherrer et al. (2016) for the winter months.

Note that such a simple linkage between temperature and precipitation on the one side and SWE on the other side for a dataset with such a high elevation range may be of limited significance for the few lowest and the highest stations. At the lowest elevations SWE may only be controlled by the conditions during the preceding month, and at the highest elevations SWE may also be influenced by November precipitation.

To investigate how well temperature and precipitation during the preceding months (see above) can explain the variability of February or April SWE, a bilinear regression model has been applied for each station. The correlation coefficient and the coefficient of determination of the statistically modeled SWE can then be used both as a measure of the strength and as a measure of the explained variance. Based on the 40-yr dataset for April SWE, Fig. 8 demonstrates that temperature is negatively and precipitation is positively correlated with SWE at the large majority of the 


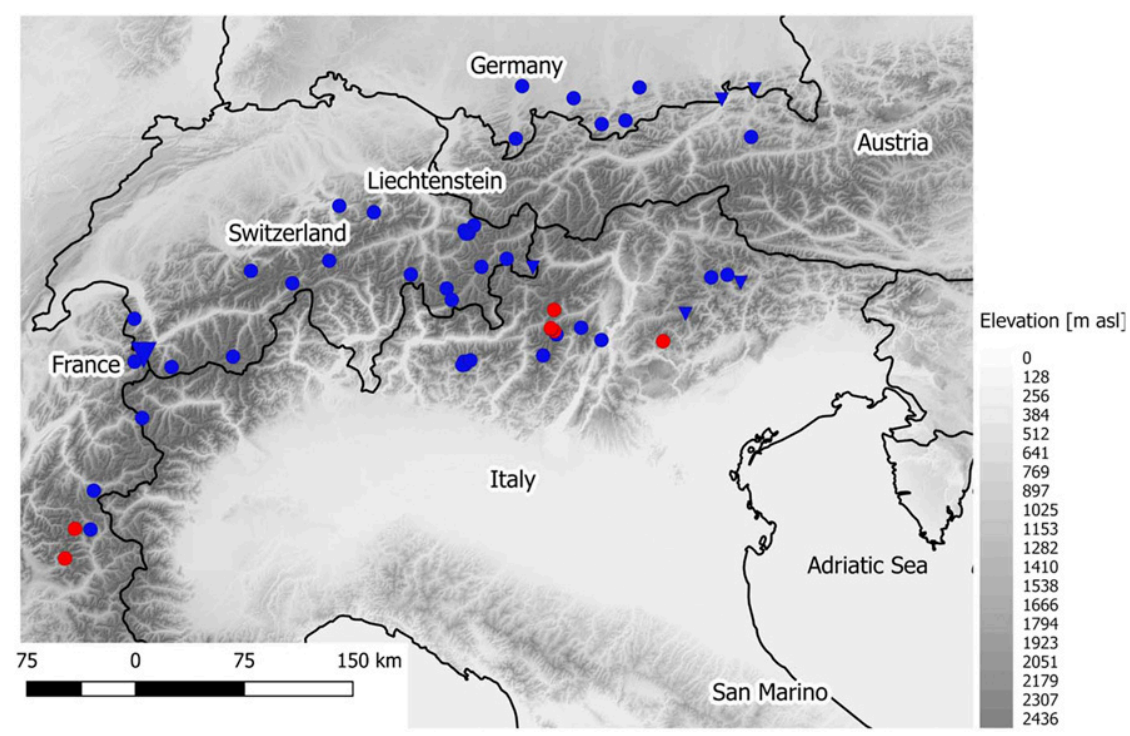

FIG. 3. Geographical distribution of the 45 year trend for February SWE. Blue specifies a negative trend, red specifies a positive trend. Large triangles indicate significant trends $(p<$ $0.05)$ and small triangles indicate weakly significant trends $(p<0.2)$. Circles represent stations with no significant trend ( $p \geq 0.2$ ). The elevation is given in gray.

stations. A dominating role of precipitation can be detected above $1400 \mathrm{~m}$ MSL, which is in good agreement with the findings of Morán-Tejeda et al. (2013) for snow depth data. Below $1000 \mathrm{~m}$ MSL, more than half of the stations show very low correlations with temperature and precipitation. Accordingly, the explained variance of the combined model is on average only $10 \%$, while the majority of higher stations demonstrate values between $30 \%$ and $60 \%$. At lower elevations precipitation often falls as rain and the snowpack can be intermittent, which causes the SWE to be dependent on the meteorological conditions after the last snow-free period, that is, not the entire December-March period. The same graph for February SWE (Fig. S4 in the supplemental material) looks similar, but the bilinear model can only explain about $5 \%$ of the variability below $1000 \mathrm{~m}$ MSL, while higher elevations show values between $10 \%$ and $40 \%$. The negative correlation with temperature and the positive correlation with precipitation are smaller than for April. These findings of an elevation-dependent response of SWE to changes in temperature and precipitation are in good agreement with results of similar studies in the western United States (Mote et al. 2005; Sospedra-Alfonso et al. 2015).

\section{Discussion}

The results demonstrate a clear Alpine-wide decline in 1 April SWE. Does the trend for this date also represent the trend for annual maximum SWE, which is the key figure for water resource management or snow loads? Because of the dynamic response of the snowpack to climatic changes, peak SWE might just have been moved to an earlier date. This question cannot be answered easily because of the monthly resolution of the investigated dataset. The weak decline observed for February SWE at least gives some indication that peak SWE might partly also be lower due to a thinner winter snowpack. A separate analysis, which was derived from a limited number of stations with biweekly measurements, corroborated this assumption. All stations revealed decreasing maximum SWE with significant negative slopes for more than half of the stations, but no indication toward an earlier occurrence of maximum SWE. This result is in agreement with the decline in annual maximum snow depths observed in the Swiss Alps (Klein et al. 2016; Marty and Blanchet 2012) and with the observed SWE loss at about $2500 \mathrm{~m}$ MSL on 1 May (see paragraph after next), which corresponds to the time of peak SWE at this elevation. The stronger decline in spring SWE compared to winter SWE is in agreement with a greater spring warming (Rebetez and Reinhard 2008), with a higher decrease in spring solid precipitation ratio as well as with a stronger decline of spring snow depth (Marty and Meister 2012).

The most striking feature when looking at the temporal evolution of winter and spring SWE (Figs. 5, 6) is the sharp drop at the end of the 1980s, which dominates the strength of the trends over the different time periods. This drop is mainly caused by a sharp temperature 


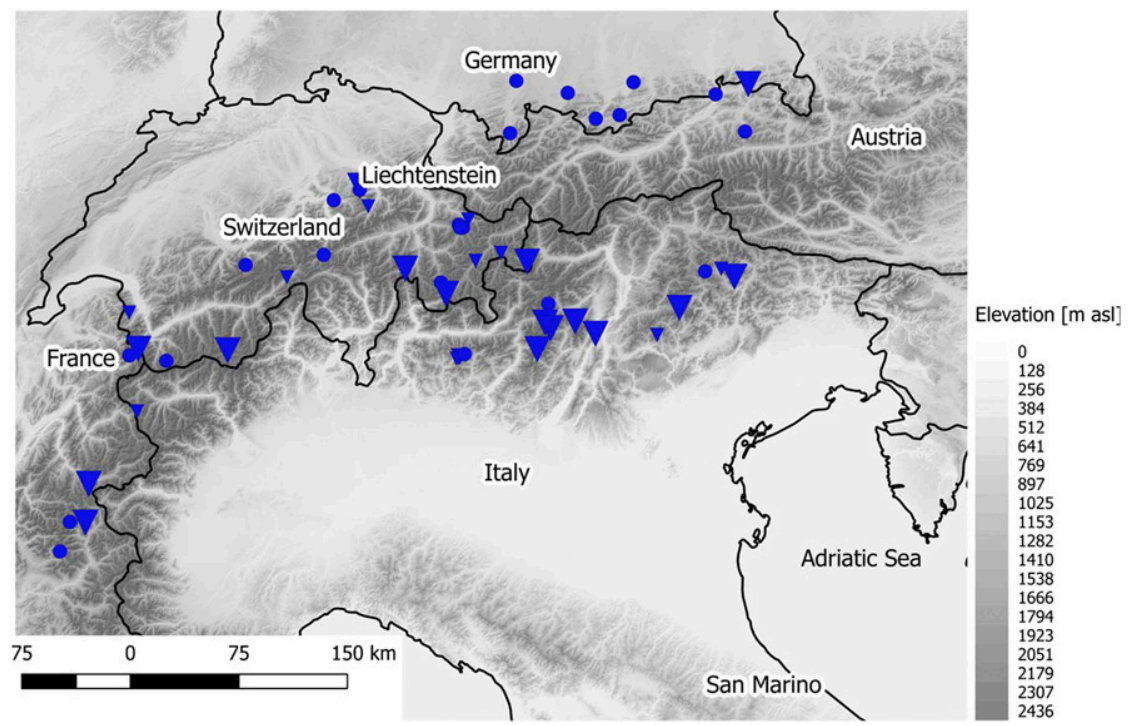

FIG. 4. As in Fig. 3, but for April.

increase, which is known in the literature but still not fully understood (see section 3d). This fact can be considered as a reminder that climate change must not necessarily be a gradual process.

The two longest time series in our dataset go back to 1937 and stem from one of the lowest (Oberstdorf, $806 \mathrm{~m}$ MSL) and one of the highest stations (Weissfluhjoch, $2540 \mathrm{~m}$ MSL) in the Alps. It has been demonstrated that the snow depth evolution of this high station shows a very similar development as the average of 50 other measurement locations from a newer network at a similar elevation in the Swiss Alps (Marty and Meister 2012). To set this long-term SWE series from Weissfluhjoch in a larger spatial and even longer temporal context, we compare it with a $100-y r$ mass balance series measured on the Clariden Firn Glacier (Huss and Bauder 2009), which is at a similar elevation but $70 \mathrm{~km}$ to the west of Weissfluhjoch. We make use of the winter mass balance series at the so-called lower snow stake (2680 m MSL) on the glacier. The winter mass balance is usually determined at the end of the accumulation season by measuring the SWE of the snow, which has accumulated since the beginning of the hydrological year. We use the 1 May homogenized time series, which can then be compared with the data from Weissfluhjoch at this index date. The Clariden Firn measurements are always higher because they are in a precipitation-rich region. The only other long-term SWE series with 1 May measurements within this elevation range in our dataset is from Petite Gouille (2410 m MSL) in the French Alps,

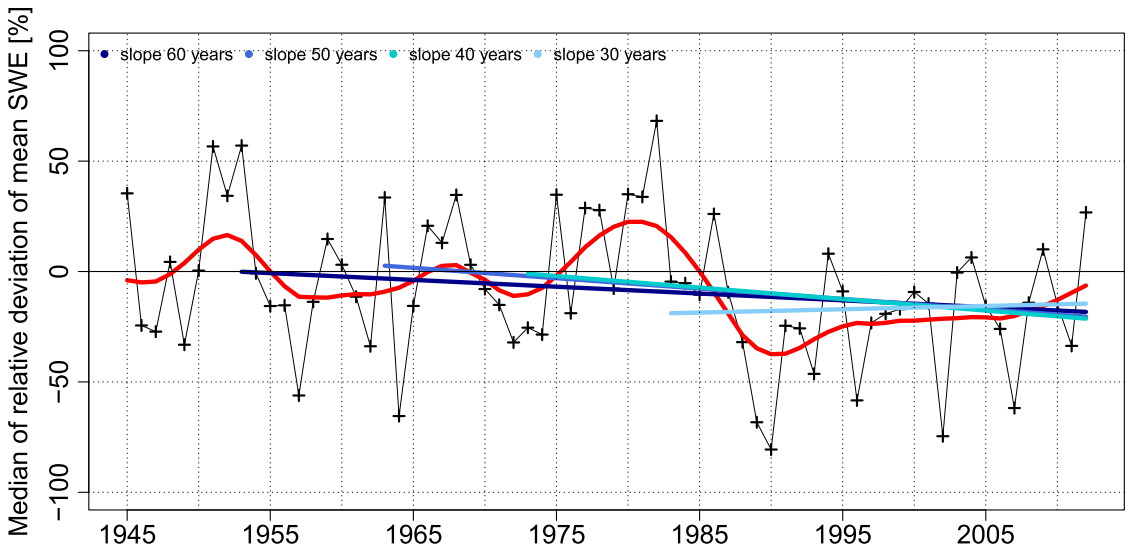

FIG. 5. The 1 Feb relative SWE deviation compared to the long-term mean (1961-90). Annual values represent the median of the deviations of all individual stations. The smoothed red curve results from a 10-yr Gaussian low-pass filter. 


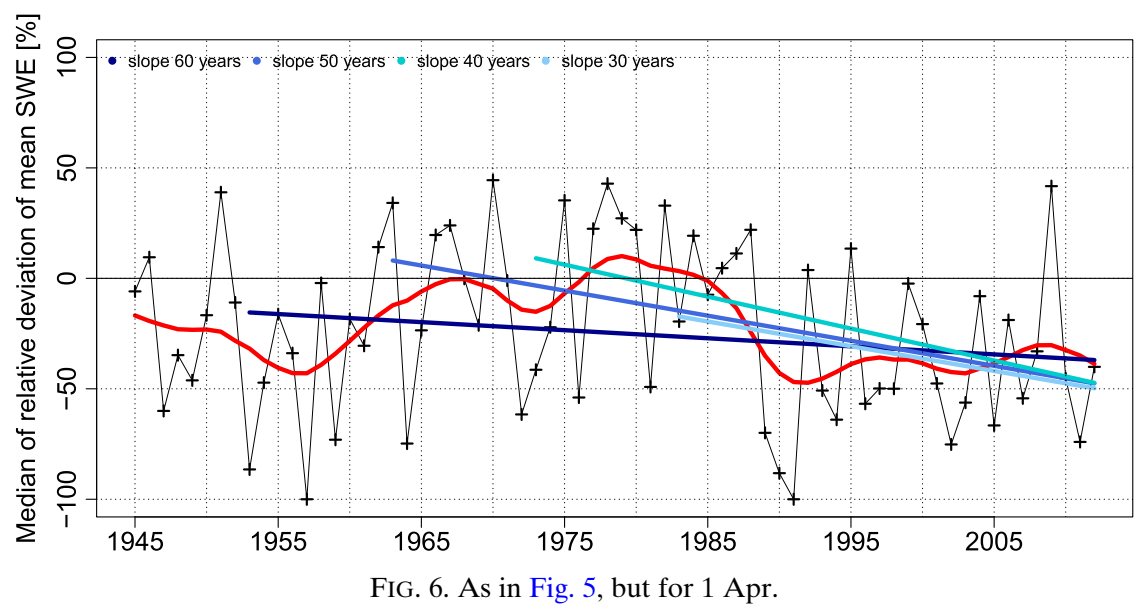

which is $260 \mathrm{~km}$ southwest of Weissfluhjoch. This time series is also shown for comparison. The normalization with the 1961-90 mean and standard deviation and subsequent application of 20-yr Gaussian low-pass filter reveals that the temporal evolution of all three series is quite similar (Fig. 9), despite the large distances between sites and despite the fact that the snowpack on high Alpine sites is often influenced by wind transport. The correlation coefficients between Weissfluhjoch and Clariden Firn and Petite Gouille are 0.79 and 0.72, respectively. The SWE measurements at all three sites demonstrate that average spring snow mass since around the year 2000 was at a record-low level since the beginning of the measurements. A comparison with the corresponding CRU temperature and precipitation series (Fig. S1 in the supplemental material) shows a good agreement with the climate influence of these parameters on the glacier mass balance found by Huss et al. (2010) based on local weather stations in the Swiss Alps. With both analyses, the record-low spring SWE values can be linked to warmer and drier than average conditions since the beginning of the 1990s. Moreover, both analyses show colder and wetter than average conditions during the 1970s and 1980s, which could easily explain the higher than average SWE values during this period.

\section{Conclusions}

This is the first study that quantitatively demonstrates that the Alpine snow water resources have been decreasing during at least the last six decades at all elevations, including the highest ones. The SWE decline is independent of latitude or longitude despite the wide range of climate regions in the Alpine domain. Low-elevation stations less frequently demonstrate significant trends than higher ones, due to the higher interannual variability. The observed decreases are clearly larger for April SWE than for February SWE. For April the majority of the stations demonstrate significant decreasing SWE trends. Trends in April SWE also show a clear elevation dependency. For the last 60 years, for example, relative April SWE loss ranges from $80 \%$ at lowest elevations to about $10 \%$ in the highest elevations. In absolute terms this implies a decrease of about $1 \mathrm{~mm} \mathrm{decade}^{-1}$ at the lowest stations and about $20 \mathrm{~mm} \mathrm{decade}^{-1}$ at the highest ones. Note that $100 \mathrm{~mm}$ spring SWE loss over the last five decades would imply 4 days earlier snow disappearance, assuming a depletion rate of $25 \mathrm{~mm} \mathrm{day}^{-1}(\sim 5 \mathrm{~cm}$ reduction in snow depth). This is in agreement with the already observed earlier snow disappearance date at two high-Alpine stations found by Marty and Meister (2012).

The observed SWE changes in the different investigated time periods could clearly be linked to changes in temperature and precipitation. SWE at both index dates is generally controlled by increasing temperatures and concurrent decreasing precipitation trends, whereas the precipitation decrease is stronger for the December-March period than for the DecemberJanuary period. The increasing temperatures cause a

\begin{tabular}{|c|c|c|c||c|c|c|c|}
\hline CRU & $\begin{array}{c}\text { SWE } \\
\text { Feb 1 }\end{array}$ & $\begin{array}{c}\text { Temp } \\
\text { DJ }\end{array}$ & $\begin{array}{c}\text { Precip } \\
\text { DJ }\end{array}$ & $\begin{array}{c}\text { SWE } \\
\text { Apr 1 }\end{array}$ & $\begin{array}{c}\text { Temp } \\
\text { DJFM }\end{array}$ & $\begin{array}{c}\text { Precip } \\
\text { DJFM }\end{array}$ \\
\hline $30 \mathrm{Y}(1983-2012)$ & $\circ$ & $\circ$ & $\circ$ & $30 \mathrm{Y}$ & $\circ$ & $\circ$ & $\nabla$ \\
\hline $40 \mathrm{Y}(1973-2012)$ & $\nabla$ & $\circ$ & $\circ$ & $40 \mathrm{Y}$ & $\nabla$ & $\circ$ & $\nabla$ \\
\hline $50 \mathrm{Y}(1963-2012)$ & $\nabla$ & $\Delta$ & $\circ$ & $50 \mathrm{Y}$ & $\nabla$ & $\Delta$ & $\nabla$ \\
\hline $60 \mathrm{Y}(1953-2012)$ & $\nabla$ & $\Delta$ & $\circ$ & $60 \mathrm{Y}$ & $\circ$ & $\Delta$ & $\circ$ \\
\hline
\end{tabular}

FIG. 7. Qualitative comparison of February and April SWE trends with concurrent trends of temperature and precipitation for different time periods. Blue specifies a negative trend, red specifies a positive trend. Large triangles indicate significant trends $(p<0.05)$ and small triangles indicate weakly significant trends $(p<0.2)$. Circles represent stations with no significant trend $(p \geq 0.2)$. 


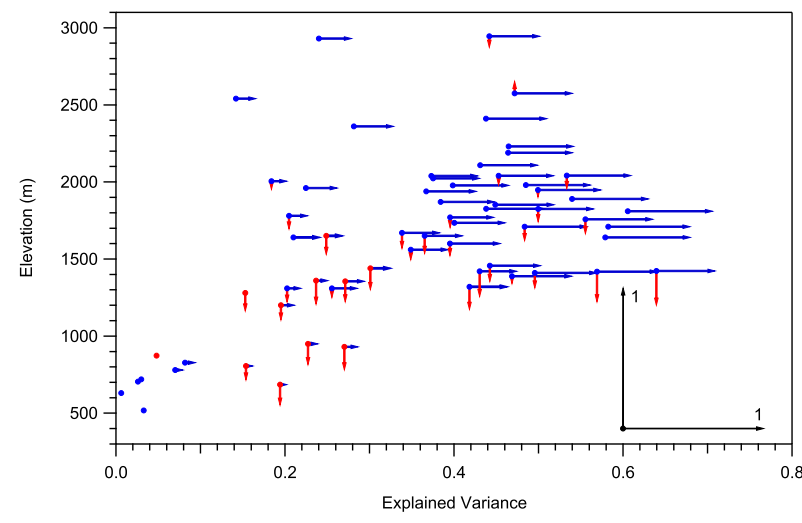

FIG. 8. Explained variance of the bilinear regression model for April SWE with temperature and precipitation (1973-2012) at each station. Red (blue) dots indicate stations where temperature (precipitation) is the dominating factor. The arrows refer to the coordinate system in black in the lower-right corner. The length of the red (blue) arrows shows the explained variance by temperature (precipitation). The direction of the arrows indicates the sign of the correlation.

decreasing snow/rain ratio (Serquet et al. 2013) and more intensive snowmelt. The lower stations are heavily influenced by the change of both parameters, especially toward spring. Therefore, relative April SWE losses are largest at low elevations. The stations at higher elevation $(>1400 \mathrm{~m})$ are mainly controlled by decreasing precipitation amounts despite the concurrent warming trend, because temperatures in the preceding months are usually still cold enough for snowfall. In contrast to other mountain regions (Mote et al. 2005; Skaugen et al. 2012), spring SWE in the Alps is therefore decreasing even at the highest locations because of decreasing precipitation amounts. However, the pronounced snow mass loss in the Alps during the last few decades had, at least concerning water management, far fewer consequences than in other mountain regions (e.g., Sierra Nevada in California; Christian-Smith et al. 2015) because the Alps are not subject to pronounced summer drought and therefore less dependent on a winter snowpack as a water resource for the dry summer months.

A comparison with a long-term winter mass balance series from a glacier in the central Alps demonstrates that current high-Alpine SWE measurements from operational networks can be used to validate the rare and valuable glacier mass balance series despite large distances between the two measurement sites. The decreasing April or May SWE even at the highest locations is also part of the reason that Alpine glaciers are strongly shrinking because a thinner snow pack implicates a shorter duration of the protecting snow cover.

There is currently no indication that the decreasing winter precipitation amounts during the recent decades can be linked to the increasing temperatures. Therefore, a rebound

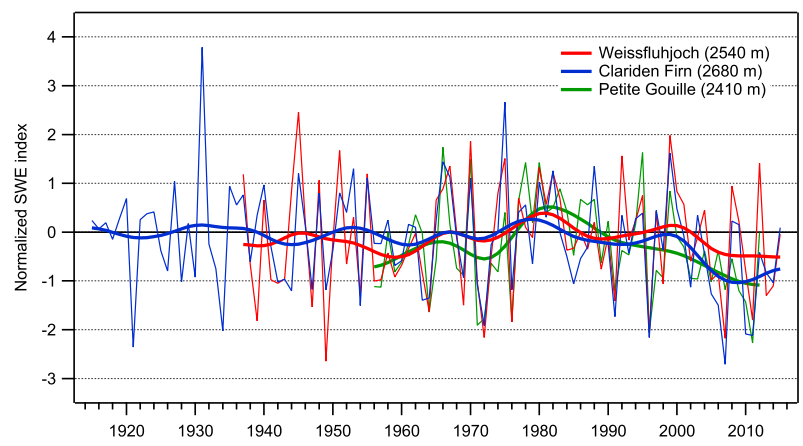

FIG. 9. Normalized SWE on 1 May of the longest high-Alpine SWE series with bimonthly data from Weissfluhjoch $(2540 \mathrm{~m}$, Switzerland) compared with the high-Alpine SWE series from Petite Gouille (2420 m, France) and with the 100-yr (1916-2015) glacier mass balance measurements from Clariden Firn $(2680 \mathrm{~m}$, Switzerland). The smoothed curve results from a 20-yr Gaussian low-pass filter.

to average or above-average precipitation values might at least at the higher locations potentially reduce the SWE loss in the next few decades. Nevertheless, in the next decades the projected further spring SWE decreases due to climate change (Schmucki et al. 2015) will reduce summer low flow of Alpine rivers (Jenicek et al. 2016) and therefore affect millions of people living on both sides of the Alps. The SWE data used in this study are available on request.

Acknowledgments. We are indebted to Deutscher Wetterdienst (DWD), Ente Nazionale per l'energia Elettrica (ENEL), Électricité de France (EDF), Meteodat $\mathrm{GmbH}$, and Hydrographischer Dienst Tirol for providing SWE data. Special appreciation goes to all observers for carrying out SWE measurements-not always in pleasant conditions-for many years. Some of the long-term SWE measurements in Switzerland are since 2016 financially supported by the Swiss Federal Office of Meteorology and Climatology within the framework of Global Climate Observing System (GCOS) Switzerland. The long-term mass balance series from Clariden Firn is maintained by Meteodat $\mathrm{GmbH}$ and the homogenized data were provided by Matthias Huss (VAW ETHZ). We also acknowledge the European Climate Assessment and Dataset (ECA\&D) project for providing the gridded climate data. Finally, we thank Marcia Phillips for polishing the English.

\section{REFERENCES}

Auer, I., and Coauthors, 2007: HISTALP-Historical Instrumental Climatological Surface Time Series of the Greater Alpine Region. Int. J. Climatol., 27, 17-46, doi:10.1002/joc.1377.

Begert, M., T. Schlegel, and W. Kirchhofer, 2005: Homogeneous temperature and precipitation series of Switzerland from 1864 to 2000. Int. J. Climatol., 25, 65-80, doi:10.1002/joc.1118. 
Bocchiola, D., and G. Diolaiuti, 2010: Evidence of climate change within the Adamello Glacier of Italy. Theor. Appl. Climatol., 100, 351-369, doi:10.1007/s00704-009-0186-x.

Christian-Smith, J., M. C. Levy, and P. H. Gleick, 2015: Maladaptation to drought: A case report from California, USA. Sustain. Sci., 10, 491-501, doi:10.1007/s11625-014-0269-1.

Cohen, J., J. Furtado, M. Barlow, V. Alexeev, and J. Cherry, 2012: Arctic warming, increasing snow cover and widespread boreal winter cooling. Environ. Res. Lett., 7, 014007, doi:10.1088/ 1748-9326/7/1/014007.

Franz, K. J., T. S. Hogue, and S. Sorooshian, 2008: Operational snow modeling: Addressing the challenges of an energy balance model for National Weather Service forecasts. J. Hydrol., 360, 48-66, doi:10.1016/j.jhydrol.2008.07.013.

Gocic, M., and S. Trajkovic, 2013: Analysis of changes in meteorological variables using Mann-Kendall and Sen's slope estimator statistical tests in Serbia. Global Planet. Change, 100, 172-182, doi:10.1016/j.gloplacha.2012.10.014.

Hantel, M., and C. Maurer, 2011: The median winter snowline in the Alps. Meteor. Z., 20, 267-276, doi:10.1127/0941-2948/ 2011/0495.

Harris, I., and P. D. Jones, 2015: Climatic Research Unit (CRU) Time-Series (TS) version 3.23 of high resolution gridded data of month-by-month variation in climate (Jan. 1901-Dec. 2014). Centre for Environmental Data Analysis, accessed $4 \mathrm{Au}-$ gust 2016, doi:10.5285/4c7fdfa6-f176-4c58-acee-683d5e9d2ed5.

Hodgkins, G. A., and R. W. Dudley, 2006: Changes in late-winter snowpack depth, water equivalent, and density in Maine, 1926-2004. Hydrol. Processes, 20, 741-751, doi:10.1002/ hyp.6111.

Howat, I. M., and S. Tulaczyk, 2005: Trends in spring snowpack over a half-century of climate warming in California, USA. Ann. Glaciol., 40, 151-156, doi:10.3189/ 172756405781813816

Huss, M., and A. Bauder, 2009: 20th-century climate change inferred from four long-term point observations of seasonal mass balance. Ann. Glaciol., 50, 207-214, doi:10.3189/ 172756409787769645.

— changes in the Swiss Alps linked to the Atlantic multidecadal oscillation. Geophys. Res. Lett., 37, L10501, doi:10.1029/ 2010 GL042616.

Jenicek, M., J. Seibert, M. Zappa, M. Staudinger, and T. Jonas, 2016: Importance of maximum snow accumulation for summer low flows in humid catchments. Hydrol. Earth Syst. Sci., 20, 859-874, doi:10.5194/hess-20-859-2016.

Jonas, T., C. Rixen, M. Sturm, and V. Stoeckli, 2008: How alpine plant growth is linked to snow cover and climate variability. J. Geophys. Res., 113, G03013, doi:10.1029/2007JG000680.

- C. Marty, and J. Magnusson, 2009: Estimating the snow water equivalent from snow depth measurements in the Swiss Alps. J. Hydrol., 378, 161-167, doi:10.1016/j.jhydrol.2009.09.021.

Jörg-Hess, S., N. Griessinger, and M. Zappa, 2015: Probabilistic forecasts of snow water equivalent and runoff in mountainous areas. J. Hydrometeor., 16, 2169-2186, doi:10.1175/ JHM-D-14-0193.1.

Klein, G., Y. Vitasse, C. Rixen, C. Marty, and M. Rebetez, 2016: Shorter snow cover duration since 1970 in the Swiss Alps due to earlier snowmelt more than to later snow onset. Climatic Change, 139, 637-649, doi:10.1007/s10584-016-1806-y.

Lehning, M., P. Bartelt, B. Brown, T. Russi, U. Stöckli, and M. Zimmerli, 1999: SNOWPACK model calculations for avalanche warning based upon a new network of weather and snow stations. Cold Reg. Sci. Technol., 30, 145-157, doi:10.1016/S0165-232X(99)00022-1.

Li, C., B. Stevens, and J. Marotzke, 2015: Eurasian winter cooling in the warming hiatus of 1998-2012. Geophys. Res. Lett., $\mathbf{4 2}$, 8131-8139, doi:10.1002/2015GL065327.

Magnusson, J., N. Wever, R. Essery, N. Helbig, A. Winstral, and T. Jonas, 2015: Evaluating snow models with varying process representations for hydrological applications. Water Resour. Res., 51, 2707-2723, doi:10.1002/2014WR016498.

Marty, C., 2008: Regime shift of snow days in Switzerland. Geophys. Res. Lett., 35, L12501, doi:10.1029/2008GL033998.

_ , and J. Blanchet, 2012: Long-term changes in annual maximum snow depth and snowfall in Switzerland based on extreme value statistics. Climatic Change, 111, 705-721, doi:10.1007/s10584-011-0159-9.

_ vations at Weissfluhjoch and its relation to other high-altitude observatories in the Alps. Theor. Appl. Climatol., 110, 573583, doi:10.1007/s00704-012-0584-3.

Mock, C. J., and K. W. Birkeland, 2000: Snow avalanche climatology of the western United States mountain ranges. Bull. Amer. Meteor. Soc., 81, 2367-2392, doi:10.1175/1520-0477(2000)081<2367: SACOTW $>2.3 . \mathrm{CO} ; 2$.

Morán-Tejeda, E., J. I. López-Moreno, and M. Beniston, 2013: The changing roles of temperature and precipitation on snowpack variability in Switzerland as a function of altitude. Geophys. Res. Lett., 40, 2131-2136, doi:10.1002/grl.50463.

Mote, P. W., A. F. Hamlet, M. P. Clark, and D. P. Lettenmaier, 2005: Declining mountain snowpack in the western North America. Bull. Amer. Meteor. Soc., 86, 39-49, doi:10.1175/ BAMS-86-1-39.

Mudryk, L. R., C. Derksen, P. J. Kushner, and R. Brown, 2015: Characterization of Northern Hemisphere snow water equivalent datasets, 1981-2010. J. Climate, 28, 8037-8051, doi:10.1175/JCLI-D-15-0229.1.

Rebetez, M., and M. Reinhard, 2008: Monthly air temperature trends in Switzerland 1901-2000 and 1975-2004. Theor. Appl. Climatol., 91, 27-34, doi:10.1007/s00704-007-0296-2.

Reid, P. C., and Coauthors, 2016: Global impacts of the 1980s regime shift. Global Change Biol., 22, 682-703, doi:10.1111/ gcb.13106.

Rohrer, M. B., and L. N. Braun, 1994: Long-term records of the snow cover water equivalent in the Swiss Alps-2. Simulation. Nord. Hydrol., 25, 65-78.

$\ldots, \ldots$, and H. Lang, 1994: Long-term records of the snow cover water equivalent in the Swiss Alps-1. Analysis. Nord. Hydrol., 25, 53-64.

Sadovský, Z., P. Faško, K. Mikulová, and J. Pecho, 2012: Exceptional snowfalls and the assessment of accidental snow loads for structural design. Cold Reg. Sci. Technol., 72, 17-22, doi:10.1016/j.coldregions.2011.12.003.

Scherrer, S. C., C. Wüthrich, M. Croci-Maspoli, R. Weingartner, and C. Appenzeller, 2013: Snow variability in the Swiss Alps 1864-2009. Int. J. Climatol., 33, 3162-3173, doi:10.1002/ joc.3653.

—, M. Begert, M. Croci-Maspoli, and C. Appenzeller, 2016: Long series of Swiss seasonal precipitation: Regionalization, trends and influence of large-scale flow. Int. J. Climatol., 36, 3673-3689, doi:10.1002/joc.4584.

Schmucki, E., C. Marty, C. Fierz, and M. Lehning, 2015: Simulations of 21 st century snow response to climate change in Switzerland from a set of RCMs. Int. J. Climatol., 35, 32623273, doi:10.1002/joc.4205. 
Schöber, J., S. Achleitner, J. Bellinger, R. Kirnbauer, and F. Schöberl, 2015: Analysis and modelling of snow bulk density in the Tyrolean Alps. Hydrol. Res., 47, 419-441, doi:10.2166/nh.2015.132.

Serquet, G., C. Marty, and M. Rebetez, 2013: Monthly trends and the corresponding altitudinal shift in the snowfall/precipitation day ratio. Theor. Appl. Climatol., 114, 437-444, doi:10.1007/ s00704-013-0847-7.

Skaugen, T., H. Bache Stranden, and T. Saloranta, 2012: Trends in snow water equivalent in Norway (1931-2009). Hydrol. Res., 43, 489-499, doi:10.2166/nh.2012.109.

Sospedra-Alfonso, R., J. R. Melton, and W. J. Merryfield, 2015: Effects of temperature and precipitation on snowpack variability in the central Rocky Mountains as a function of elevation. Geophys. Res. Lett., 42, 4429-4438, doi:10.1002/ 2015 GL063898.

Steger, C., S. Kotlarski, T. Jonas, and C. Schär, 2013: Alpine snow cover in a changing climate: A regional climate model perspective. Climate Dyn., 41, 735-754, doi:10.1007/ s00382-012-1545-3.

Stewart, I., 2009: Changes in snowpack and snowmelt runoff for key mountain regions. Hydrol. Processes, 23, 78-94, doi:10.1002/hyp.7128.

Yamaguchi, S., O. Abe, S. Nakai, and A. Sato, 2011: Recent fluctuations of meteorological and snow conditions in Japanese mountains. Ann. Glaciol., 52, 209-215, doi:10.3189/ 172756411797252266. 